\title{
Map-based assessment of older adults' life space: validity and reliability
}

Timo Hinrichs ${ }^{1 *}$ (D), Adriana Zanda ${ }^{2}$, Michelle P. Fillekes ${ }^{2,3}$, Pia Bereuter ${ }^{4}$, Erja Portegijs ${ }^{5}$, Taina Rantanen ${ }^{5}$, Arno Schmidt-Trucksäss ${ }^{1}$, Andreas W. Zeller ${ }^{6}$ and Robert Weibel ${ }^{2,3}$

\begin{abstract}
Background: Map-based tools have recently found their way into health-related research. They can potentially be used to quantify older adults' life-space. This study aimed to evaluate the validity (vs. GPS) and the test-retest reliability of a map-based life-space assessment (MBA).

Methods: Life-space of one full week was assessed by GPS and by MBA. MBA was repeated after approximately 3 weeks. Distance-related (mean and maximum distance from home) and area-related (convex hull, standard deviational ellipse) life-space indicators were calculated. Intraclass correlations (MBA vs. GPS and test-retest) were calculated in addition to Bland-Altman analyses (MBA vs. GPS).

Results: Fifty-eight older adults (mean age 74, standard deviation 5.5 years; 39.7\% women) participated in the study. Bland-Altman analyses showed the highest agreement between methods for the maximum distance from home. Intraclass correlation coefficients ranged between 0.19 ( $95 \%$ confidence interval 0 to 0.47 ) for convex hull and 0.72 (95\% confidence interval 0.52 to 0.84 ) for maximum distance from home. Intraclass correlation coefficients for test-retest reliability ranged between 0.04 ( $95 \%$ confidence interval 0 to 0.30 ) for convex hull and 0.43 ( $95 \%$ confidence interval 0.19 to 0.62 ) for mean distance from home.
\end{abstract}

Conclusions: While acceptable validity and reliability were found for the distance-related life-space parameters, MBA cannot be recommended for the assessment of area-related life-space parameters.

Keywords: Geographic information systems, Environment, Mobility, Aged

\section{Background}

Life-space can be defined as the "spatial extent in which a person moves within a specified period" ( [1] , p. 155). It results from "the interaction between intrinsic capabilities of the person and the demands of the extrinsic environment" ([1], p. 155), including the physical, sociocultural, and the economic environment. In older adults, life-space is positively associated with social participation [2], quality of life [3], and physical activity [4, 5]. Limited life-space

\footnotetext{
* Correspondence: timo.hinrichs@unibas.ch

'Division of Sports and Exercise Medicine, Department of Sport, Exercise and Health, University of Basel, Birsstrasse 320 B, 4052 Basel, Switzerland

Full list of author information is available at the end of the article
}

predicts disability in basic activities of daily living [6], falls and fractures [7], and mortality [8].

Until now, epidemiological studies mostly relied on questionnaires to measure life-space. These offer advantages such as low cost and time-efficiency. However, the geospatial information gained from questionnaires is rather coarse. As an example, the frequently used University of Alabama at Birmingham Study of Aging Life-Space Assessment assesses the subjective extent of an individual's movement categorized into five spatial levels, ranging from the participant's bedroom to places outside the participant's home town [9]. Nowadays, global positioning system (GPS) technology offers the chance to objectively and much more precisely measure

(c) The Author(s). 2020 Open Access This article is licensed under a Creative Commons Attribution 4.0 International License, which permits use, sharing, adaptation, distribution and reproduction in any medium or format, as long as you give appropriate credit to the original author(s) and the source, provide a link to the Creative Commons licence, and indicate if changes were made. The images or other third party material in this article are included in the article's Creative Commons licence, unless indicated otherwise in a credit line to the material. If material is not included in the article's Creative Commons licence and your intended use is not permitted by statutory regulation or exceeds the permitted use, you will need to obtain permission directly from the copyright holder. To view a copy of this licence, visit http://creativecommons.org/licenses/by/4.0/ The Creative Commons Public Domain Dedication waiver (http://creativecommons.org/publicdomain/zero/1.0/) applies to the data made available in this article, unless otherwise stated in a credit line to the data. 
life space [10-12]. GPS devices allow tracking an individual's location at high spatial and temporal resolution [13]. While high-end GPS devices can achieve decimetre accuracy, typical portable consumer GPS devices nowadays reach a positioning accuracy of 2-3 $\mathrm{m}$ under normal conditions [14]. However, barriers towards using GPS in large-scale studies include high costs and an elaborate handling of devices imposing a burden on participants; i.e., participants have to carry around the GPSenabled device whenever they leave their home and the device's battery has to be charged regularly [13]. A number of geographic approaches have been suggested aiming to quantify an individual's life space based on GPS data, including the maximum distance from home [15], the area of convex hull $[1,16,17]$, and the area of standard deviational ellipse $[16,18,19]$ (see methods section). Additional qualitative information (e.g. on the purpose of an activity) cannot be captured directly from GPS, although, there are a number of health-related measures that can be derived from GPS tracking data, including use of transportation [20], time spent out of home [21], and exposure to certain environments (such as green spaces, fast-food restaurants or supermarkets [22]).

Questionnaire tools based on interactive digital maps, usually referred to as 'Public Participation Geographic Information Systems' [23] or 'SoftGIS' [24, 25], allow the combination of qualitative data (i.e. the "soft" knowledge produced by participants) with objective geographic information system data (e.g. street network, physical structure, building density etc.). In the context of our study, advantages of paper-based life-space questionnaires and GPS are combined: low cost, time efficiency, low burden on participants, and fine-grained spatial location information. Additional qualitative information, e.g. on the purpose of visiting a certain location, on the use of transportation modes, on the need for personal assistance or on environmental barriers and facilitators of mobility, may be collected simultaneously [24-27]. Map-based tools have recently found their way into health-related research [23, 25-28], but only since very recently are being used to quantify people's life space [29].

For the present study, a questionnaire tool based on interactive digital maps aiming to assess older adults' life-space was developed [30]. The map-based assessment (MBA) consisted of a retrospective evaluation of all places visited within the past 7 days and was assisted by a trained interviewer. It started with a short tutorial on how to navigate through the questionnaire and on how to mark locations on the map. In a first step, participants were asked to mark their home on the map. After that - following the example of the University of Alabama at Birmingham Study of Aging Life-Space Assessment visited places as well as the frequency of visits were assessed in 3 consecutive steps referring to the three levels: 1) in the neighbourhood; 2) outside the neighbourhood, but within town; and 3) outside town.

The aim of this study was to evaluate the validity of MBA of older adults' life space versus GPS. Furthermore, test-retest reliability of the MBA was investigated.

\section{Methods}

\section{Study design and participants}

This validity (cross-sectional) and reliability (test-retest) study was approved by the Ethics Committee Northwest/ Central Switzerland (Reg.-No. 2016-01259). To be eligible for the study, subjects had to be community-dwelling, aged 65 or older, and be able to communicate appropriately. Subjects had to report that they regularly leave their home ( $\geq 3$ times per usual week) and be able to walk short distances without the help of another person. Only those who were unable to visit the study centre were excluded. All participants provided written informed consent.

A convenience sample was recruited for this study. Potential participants were approached by study personnel in general practitioner practices as well as through adult education centres, clubs and service organizations for older adults. People who expressed interest in participating in studies at the corresponding author's institution in the past were also approached.

Assessments took place in the study centre and in participants' daily lives carrying a GPS tracking device. Assessments were conducted in four steps:

1 Baseline (study centre): assessment of basic participant characteristics; hand-out of GPS device.

2 Observation period (participants' daily lives): one week of continuous ambulatory GPS measurement.

3 First follow-up (study centre): hand-in of GPS device; assessment of life space by MBA. The MBA referred to the past seven days, i.e. the period when GPS measurements took place.

4 Second follow-up (study centre; about 3 weeks after first follow-up): retest of MBA. Again, the MBA referred to the past seven days.

\section{Measures \\ Map-based assessment of life space}

The MBA consisted of a retrospective evaluation of outdoor activities of the past 7 days by a web-based questionnaire using digital geographical maps [30]. The questionnaire started with a short tutorial on how to mark (or delete) locations on the map and on how to navigate through the screens. The application splits the screen into a left and right pane with questions on the left and an interactive map on the right pane (Fig. 1). Whenever, a location was marked (by moving the cursor to the correct location on the map and clicking the left mouse-button), a pop-up window opened automatically 


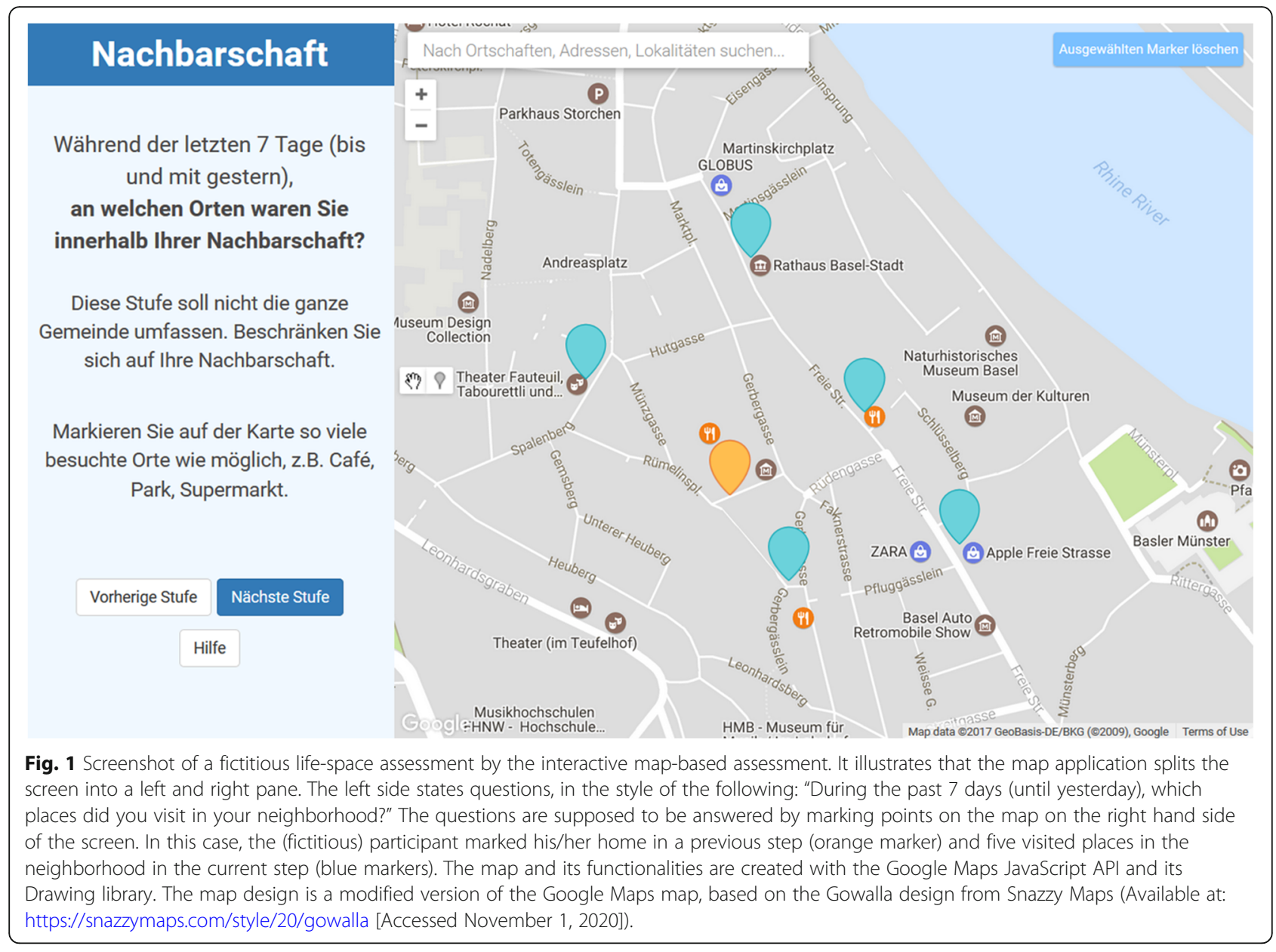

and asked the participant for the frequency of visiting this location within the past 7 days. In case a marker was set to a wrong location, it could always be deleted or dragged to another location. A trained interviewer was always present and helped the participant in case of any problems, e.g. with handling the user interface or with understanding questions or required tasks. In the context of our study, major advantages of using digital maps (instead of paper maps) included: (a) the possibility to automatically search for addresses and specific locations (by typing the location's name into a search bar), (b) the flexible scale of the map (participants could zoom in an out), additionally facilitating the identification of visited places and improving location accuracy, and (b) the simplified data handling with geographic coordinates of a location being directly saved to an electronic database. After the tutorial, participants were asked to mark their home on the map. After that, visited places and frequency of visits were assessed in 3 steps (one screen per step): 1) in the neighbourhood; 2) outside the neighbourhood, but within town; and 3) outside town.

The captured longitude and latitude coordinates were projected to a metric coordinate system [31]. The following previously suggested distance-related and arearelated indicators of life-space were calculated: mean distance of visited locations from home (straight line distance) [1], maximum distance from home (straight line distance) [15], area of convex hull [1, 16, 17], and area of standard deviational ellipse $[16,18,19]$. The convex hull is the smallest convex polygon that encompasses all points of a point set [18]. The standard deviational ellipse measures the dispersion and orientation of a point set; we used the 'one'-standard deviational ellipse containing $68 \%$ of all points. This life-space measure is less sensitive to outliers than the maximum distance and the convex hull $[19,32]$. Calculations of mean distance and standard deviational ellipse were weighted for the frequency of visiting a location [19].

\section{GPS-based assessment of life space}

During the observation period, participants wore a small portable GPS tracking device (uTrail, CDD Ltd., Athens, Greece) for 7 consecutive full days. Participants received instructions on correct device handling prior to the observation period and a phone call during the observation period to check for potential handling problems. Again, 
mean distance and maximum distance from home as well as convex hull and standard deviational ellipse were calculated. GPS data and data collected with MBA of an example participant are shown in Fig. 2; life space of the respective participant indicated by convex hull and standard deviational ellipse derived from GPS and MBA data are also illustrated in Fig. 2. GPS-based assessment of life space was considered as being valid, if the following criteria were fulfilled: minimum of 4 days with at least $9 \mathrm{~h}$ between the first and the last GPS fix of the day, including at least 2 weekdays and at least one weekend day [33-35].

\section{Basic participant characteristics}

Age, sex, living alone, living area (urban/suburban/rural) and availability of a private car were assessed by selfreport. Education was measured as total years of formal education including school and vocational training [36]. Financial hardship was assessed by the question 'did you experience financial difficulties that restricted your everyday life (participation) over the past four weeks?'; answer categories were 'had no impact', 'has complicated my life somewhat', and 'has complicated my life massively' [37]. Weight and height were measured by a trained assessor; body mass index was calculated. Frequency of falls and use of a walking aid were assessed by self-report [38]. Cognitive state was evaluated by the Mini-Mental State Examination [39].

\section{Statistical analyses}

Participant characteristics were analysed descriptively. In order to evaluate the validity of MBA versus GPS, lifespace parameters derived from MBA and GPS were assessed for agreement between methods by performing Bland-Altman-Analyses and by calculating intraclass correlations (type A,1) [40,41]. As a measure of testretest reliability of the MBA, intraclass correlations (type A,1) were calculated [41]. SPSS Statistics 24 (IBM Inc., Armonk, NY, USA) was used for statistical analyses; the level of significance was set at $p \leq 0.05$.

\section{Sample size}

Sample size calculation was based on the Bland-AltmanAnalyses for agreement between MBA and GPS.

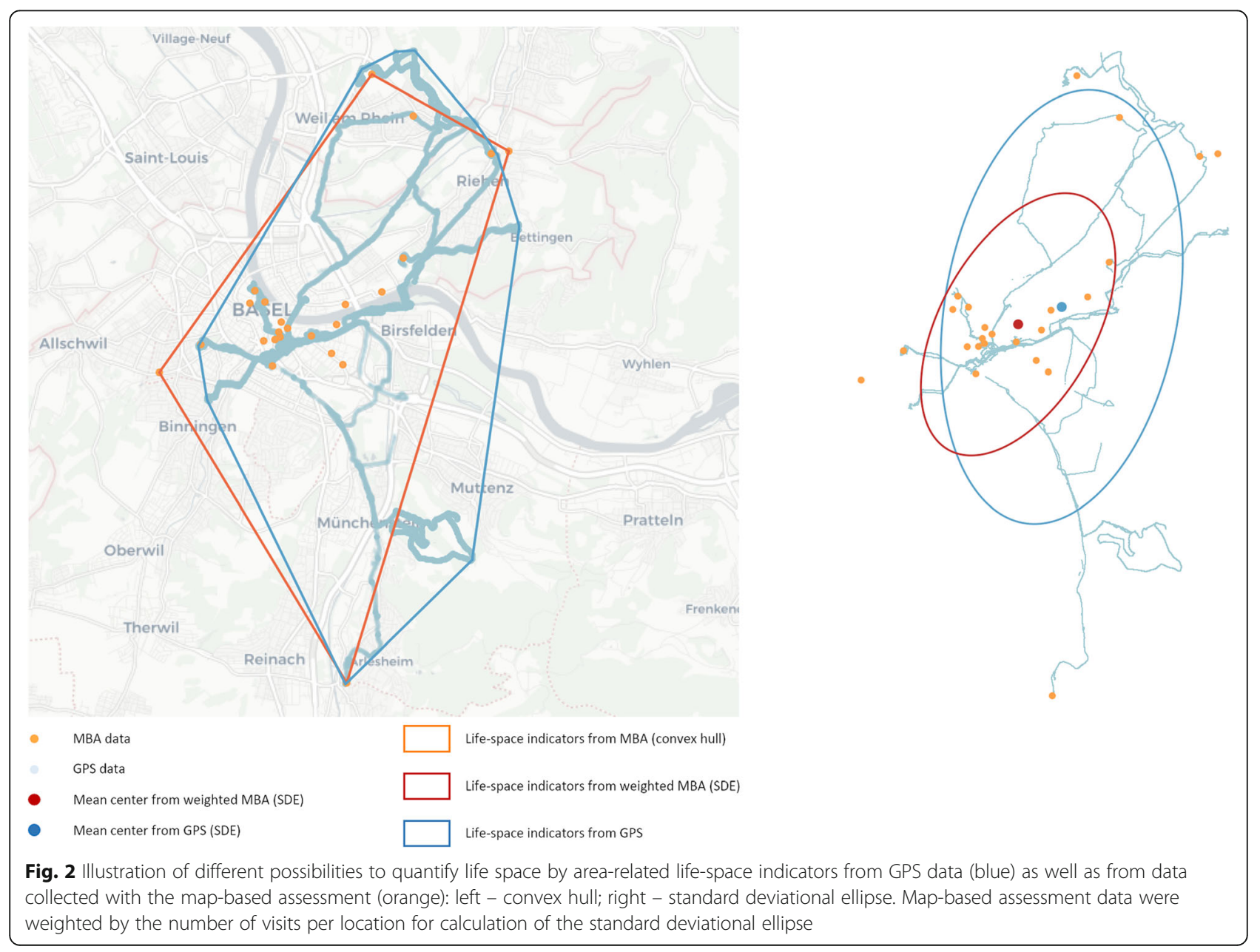


Independent of the outcome parameter used, a sample size of 47 results in an accuracy of $\pm 0.5 \% s$ for the estimation of limits of agreement, where $s$ is the standard deviation of the differences between measurements by the two methods [40, 42]. Accounting for $15 \%$ of participants with invalid GPS measurements, the target sample size was 56.

\section{Results}

\section{Participants}

Fifty-eight older adults (mean age 74, standard deviation 5.5 years; $39.7 \%$ women) participated in the study (Table 1).

\section{Validity}

Twenty participants did not meet the above-mentioned criteria for a valid GPS-based life-space assessment; GPS data of another participant showed massive errors due to a broken device. Therefore, analyses of agreement between GPS and MBA refer to the remaining 37 participants. Those excluded had a higher mean age than those analyzed (76, standard deviation 5.1 years vs. 73,

Table 1 Basic participant characteristics $(N=58)$

\begin{tabular}{|c|c|c|}
\hline Characteristic & Mean \pm SD or $n(\%)$ & Min.; Max. \\
\hline \multicolumn{3}{|l|}{ Sociodemographics } \\
\hline Age, mean $\pm S D$ & $74.0 \pm 5.5$ & $65 ; 87$ \\
\hline Female, n (\%) & $23(39.7)$ & \\
\hline Living alone, n (\%) & $21(36.2)$ & \\
\hline \multicolumn{3}{|l|}{ Living area, n (\%) } \\
\hline Urban & $29(50.0)$ & \\
\hline Suburban & $22(37.9)$ & \\
\hline Rural & $7(12.1)$ & \\
\hline Private car available, $\mathrm{n}(\%)$ & 45 (77.6) & \\
\hline Years of education, n (\%) & $13.8 \pm 3.1$ & $8 ; 22$ \\
\hline \multicolumn{3}{|l|}{ Financial hardship, n (\%) } \\
\hline No difficulties & $55(94.8)$ & \\
\hline Some difficulties & $2(3.4)$ & \\
\hline Severe difficulties & $1(1.7)$ & \\
\hline \multicolumn{3}{|l|}{ Health-related parameters } \\
\hline Body Mass Index, mean \pm SD & $25.4 \pm 3.5$ & $18.8 ; 34.3$ \\
\hline \multicolumn{3}{|c|}{ Number of falls in past 12 months, $n$ (\%) } \\
\hline 0 & $41(70.7)$ & \\
\hline 1 & $12(20.7)$ & \\
\hline$\geq 2$ & $5(8.6)$ & \\
\hline \multicolumn{3}{|c|}{ Use of walking aid in past week, n (\%) } \\
\hline No aid & $57(98.3)$ & \\
\hline Walking stick & $1(1.7)$ & \\
\hline MMSE Count (0-30), mean \pm SD & $27.6 \pm 2.3$ & $17 ; 30$ \\
\hline
\end{tabular}

SD Standard deviation; MMSE Mini Mental State Examination standard deviation 5.6 years) and they were more frequently female (50\% vs. 35\%). Bland-Altman-Analyses (Fig. 3) showed the highest agreement between methods for the maximum distance from home with a mean difference of $-2.07 \mathrm{~km}$ and narrow limits of agreement (Fig. 3, B). The agreement was lowest for convex hull area with a mean difference of $-477 \mathrm{~km}^{2}$, wide limits of agreement, and a tendency towards decreasing agreement with higher mean of methods (Fig. 3, C). This was also reflected by the intraclass correlation coefficients, ranging between 0.19 (convex hull; 95\% confidence interval 0 to 0.47 ) and 0.72 (maximum distance from home; 95\% confidence interval 0.52 to 0.84 ) (Table 2), the latter being interpretable as "substantial" according to Landis and Koch [43].

\section{Reliability}

One participant dropped out between first and second follow-up. Another participant only marked one visited location on the map at second follow-up so that arearelated parameters could not be calculated. Therefore, reliability analyses refer to 57 participants for mean and maximum distance from home and 56 participants for convex hull and standard deviational ellipse. Mean time period between the two MBAs was 22.3, standard deviation 7.9 days. Intraclass correlation coefficients are shown in Table 3; they were not statistically significant for standard deviational ellipse and convex hull [43].

\section{Discussion}

This study investigated the validity and reliability of an MBA of older adults' life space. Distance-related and area-related life-space indicators were considered. The highest agreement between methods was found for the maximum distance from home. The highest test-retest reliability was found for the mean distance from home.

The present MBA assessed the life space retrospectively for a whole week. Therefore, the most important factor limiting agreement between the two methods was probably recall bias; i.e. participants did not remember all visited places. Similarly to Ullrich et al., who developed a modified version of the University of Alabama at Birmingham Study of Aging Life-Space Assessment for older persons with cognitive impairment [44], we limited the assessment period to one week in order to reduce this sort of bias. In our sample, only one participant had a Mini Mental State Examination count below 24 [45]; i.e. cognitive impairment was probably not a very relevant issue. A potential option to reduce recall bias in future map-based tools would be the daily (or even more frequent) assessment of visited places. This would however limit the possibility to provide personal assistance by a trained interviewer and participants would have to be provided with regular access to the tool. It seems that 

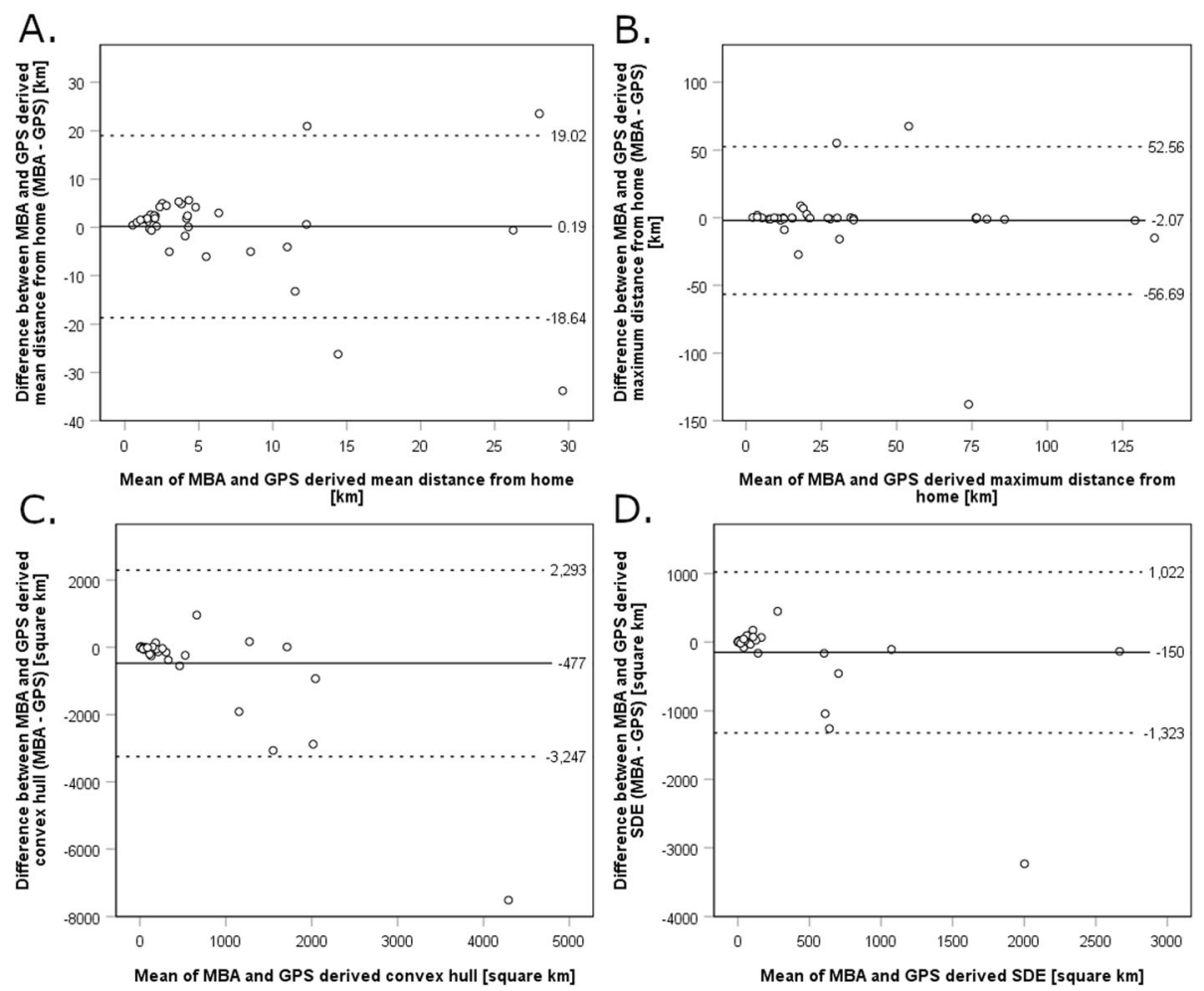

Fig. 3 Bland-Altman plots illustrating the agreement of mean distance from home (a), maximum distance from home (b), convex hull (c) and standard deviational ellipse (SDE) (d) derived from the map-based assessment (MBA) and GPS measurements. The continuous horizontal line shows the mean difference between measurements by the two methods; the dashed lines show the limits of agreement, defined as the mean difference plus and minus 1.96 times the standard deviation of the differences

participants remembered the visited place with the furthest distance from home quite well, which was reflected by a high agreement between methods for this parameter. Even though this parameter only provides a very limited picture of a person's life space, future studies using digital maps might choose to limit their life-space assessment to this single parameter.

Shareck et al. (2013) developed a map-based tool to obtain information on people's 'regularly visited locations' [46]. Participants of their validation study were asked to provide details about the locations of predefined habitual activities. The convex hull areas $(n=$ 23; mean age 37, standard deviation 12 years) derived from the MBA (median convex hull area $2.6 \mathrm{~km}^{2}$, interquartile range 1.0 to $6.3 \mathrm{~km}^{2}$ ) were smaller than those derived from an 8-day GPS tracking (median convex hull area $27.8 \mathrm{~km}^{2}$, interquartile range 11.7 to $186.9 \mathrm{~km}^{2}$ ). More recently, a study by Kestens et al. (2018) compared convex hull areas derived from a map-based tool ('VERI TAS') with convex hull areas derived from 7-day GPS tracking [47]. Similar to the tool described by Shareck et al., the VERITAS questionnaire assesses destinations

Table 2 Intraclass correlations between map-based assessment and the respective GPS parameters

\begin{tabular}{|c|c|c|c|c|c|c|c|c|c|c|c|c|c|c|c|c|}
\hline \multirow[b]{4}{*}{$\begin{array}{l}\text { GPS-based assessment of } \\
\text { life-space }\end{array}$} & \multicolumn{16}{|c|}{ Map-based assessment of life space } \\
\hline & \multicolumn{4}{|c|}{$\begin{array}{l}\text { Mean distance from } \\
\text { home }(\mathrm{km})\end{array}$} & \multicolumn{4}{|c|}{$\begin{array}{l}\text { Maximum distance from } \\
\text { home }(\mathrm{km})\end{array}$} & \multicolumn{4}{|c|}{ Convex hull $\left(\mathrm{km}^{2}\right)$} & \multicolumn{4}{|c|}{$\begin{array}{l}\text { Standard deviational } \\
\text { ellipse }\left(\mathrm{km}^{2}\right)\end{array}$} \\
\hline & \multirow[b]{2}{*}{$\mathrm{N}$} & \multirow[b]{2}{*}{ ICC } & \multicolumn{2}{|l|}{$95 \% \mathrm{Cl}$} & \multirow[b]{2}{*}{$\mathbf{N}$} & \multirow[b]{2}{*}{ ICC } & \multicolumn{2}{|l|}{$95 \% \mathrm{Cl}$} & \multirow[b]{2}{*}{$N$} & \multirow[b]{2}{*}{ ICC } & \multicolumn{2}{|l|}{$95 \% \mathrm{Cl}$} & \multirow[b]{2}{*}{$N$} & \multirow[b]{2}{*}{ ICC } & \multicolumn{2}{|l|}{$95 \% \mathrm{Cl}$} \\
\hline & & & Lower & Upper & & & Lower & Upper & & & Lower & Upper & & & Lower & Upper \\
\hline Mean distance from home $(\mathrm{km})$ & 37 & $0.42 *$ & 0.11 & 0.66 & & & & & & & & & & & & \\
\hline Maximum distance from home $(\mathrm{km})$ & & & & & 37 & $0.72^{*}$ & 0.52 & 0.84 & & & & & & & & \\
\hline Convex hull $\left(\mathrm{km}^{2}\right)$ & & & & & & & & & 37 & 0.19 & 0 & 0.47 & & & & \\
\hline Standard deviational ellipse $\left(\mathrm{km}^{2}\right)$ & & & & & & & & & & & & & 37 & $0.55^{*}$ & 0.29 & 0.74 \\
\hline
\end{tabular}

ICC Intraclass Correlation Coefficient; CI Confidence Interval 
Table 3 Test-retest reliability of the map-based assessment (first/second follow-up)

\begin{tabular}{llllll}
\hline & & & \multicolumn{2}{c}{$\mathbf{9 5 \%} \mathrm{Cl}$} \\
\cline { 5 - 6 } Measure & $\mathbf{N}$ & ICC & Lower & Upper \\
\hline Mean distance from home $(\mathrm{km})$ & 57 & $\mathbf{0 . 4 3 *}$ & 0.19 & 0.62 \\
Maximum distance from home $(\mathrm{km})$ & 57 & $\mathbf{0 . 2 6 *}$ & $<0.01$ & 0.49 \\
Convex hull $\left(\mathrm{km}^{2}\right)$ & 56 & 0.04 & 0 & 0.30 \\
Standard deviational ellipse $\left(\mathrm{km}^{2}\right)$ & 56 & 0.14 & 0 & 0.38 \\
\hline
\end{tabular}

ICC Intraclass Correlation Coefficient; Cl Confidence Interval

$* \mathrm{p} \leq .05$

within predefined categories that participants visit regularly without specifying a particular recall period. Again, MBA and GPS convex hulls areas differed markedly (median convex hull area $33.0 \mathrm{~km}^{2}$, interquartile range 7.0 to $368.8 \mathrm{~km}^{2}$; and 147.9 , IQR 50.3 to $1348.6 \mathrm{~km}^{2}$, respectively) ( $n=234$; mean age 57.8 , standard deviation 11.6 years). The tendency towards finding smaller convex-hull areas by MBA compared to GPS seems to be in line with our results. However, the difference between MBA and GPS was much larger in our sample of older adults (mean difference $477 \mathrm{~km}^{2}$ for the convexhull area). In conclusion, asking for 'regularly visited locations' within predefined activity categories (instead of all activities of the past week) might further contribute towards a reduction of recall bias.

Even though GPS measurements can be considered as 'gold standard' with respect to spatio-temporal accuracy of the data, they also have many defaults such as weak or no satellite signal or compliance issues (e.g. people not wearing or charging the devices). This may also limit the agreement between methods. As the GPS-based assessment was our 'gold-standard', we chose a rather strict definition of a 'valid' GPS measurement. This led to a larger number of invalid measurements than initially expected. However, a sample size of 37 generally still results in an accuracy of $\pm 0.56 \%$ for the estimation of limits of agreement in Bland-Altman Analyses [40]. The resulting widening of the limits of agreement as well as the widening of the $95 \%$ confidence intervals of the calculated intraclass correlation coefficients did not affect our conclusions. Sensitivity analyses with less strict definitions of a 'valid' GPS measurement did not markedly change the results.

Choosing a rather short recall period for the MBA of only one week might have contributed to the limited test-retest reliability. While the reliability was fair to moderate for the two distance-related life-space parameters, intraclass correlations did not reach statistical significance for the two area-related parameters. To explain the low reliability of the two area-related parameters, it has to be considered that the life space of two different weeks was assessed and especially in a highly functioning sample like ours (only one participant using a walking aid; only 5 participants with 2 or more falls in the past year), life space may vary significantly from week to week. In comparison, Baker et al. showed an intraclass correlation coefficient between test and retest (2-week follow-up) of the LSA composite score of 0.96 (95\% confidence interval 0.95 to 0.97 ), which assesses life space of the past 4 weeks, takes the degree of independence into account and, in contrast to the MBA, includes in-house movement [9]. Ullrich et al. found an intraclass correlation coefficient between test and retest (2-day followup) for their modified 1-week LSA composite score of 0.91 (95\% confidence interval 0.87 to 0.94 ) [44].

In conclusion, there is a tension between the need for lower recall durations - in order to minimize recall bias - and longer assessment periods - in order to minimize variability - which has to be considered by developers of future MBAs. As a first step, further research on the variability of life-space in older adults is needed. The optimal assessment period needed in order to reliably capture an older adults' activity routine is still largely unknown. A recent GPS study suggested that, for working-age adults, the largely applied 7-day measurement period should at least be extended to 14 days for reliable estimates of an individual's activity routine [22]. As a second step, possibilities to minimize recall bias should be explored. Considering the rapidly increasing proportion of smartphone users in the older population $[48,49]$, the implementation of an MBA into an easy-touse smartphone application (with daily or even more frequent assessments) might be a feasible option for future studies. Making use of a smartphone application would even allow to combine the advantages of an MBA with the technological measurement properties offered by modern smartphones (including GPS and inertial measurement units) [12].

\section{Conclusions}

This study contributes to the exploration of possibilities and limitations of using digital geographical maps in health-related research in older adults. Acceptable validity and reliability of the MBA were found for the distance-related life-space parameters. In the presented form, MBA cannot be recommended for the assessment of area-related life-space parameters, at least in a sample of highly functioning older people and for a recall period of only one week.

\section{Abbreviations}

GPS: Global Positioning System; MBA: Map-Based Assessment

\section{Acknowledgements}

The authors would like to thank Sandra Baumann, Jennifer Schmid and Sophie Sutter for their contribution to recruitment, data collection and data management. 


\section{Authors' contributions}

Conceptualisation of the project: TH, RW, MPF, PB, AZ. Contribution to study design: all authors. Project management: TH, RW, MPF, AZ. Recruitment and support of general practitioners: AWZ. Recruitment of participants: AZ. Data collection and data management: AZ, TH. Design of map-based assessment: AZ, TH, MPF, PB, EP. Programming of map-based assessment: AZ. Processing of GPS data: AZ, MPF. Statistical analyses: TH, AZ. Manuscript draft: TH, AZ Critical revision and final approval of manuscript: all authors.

\section{Funding}

There was no external funding for this study.

\section{Availability of data and materials}

The datasets used and/or analysed during the current study are available from the corresponding author on reasonable request.

\section{Ethics approval and consent to participate}

This study was approved by the Ethics Committee Northwest/Central Switzerland (Reg.-No. 2016-01259). All participants provided written informed consent.

\section{Consent for publication}

Not applicable.

\section{Competing interests}

The authors declare that they have no competing interests.

\section{Author details}

'Division of Sports and Exercise Medicine, Department of Sport, Exercise and Health, University of Basel, Birsstrasse 320 B, 4052 Basel, Switzerland. 2Department of Geography, University of Zurich, Zurich, Switzerland. ${ }^{3}$ University Research Priority Program "Dynamics of Healthy Aging", University of Zurich, Zurich, Switzerland. "Institute of Geomatics Engineering, University of Applied Sciences and Arts, Northwestern Switzerland, Muttenz, Switzerland. ${ }^{5}$ Faculty of Sport and Health Sciences and Gerontology Research Center, University of Jyvaskyla, Jyvaskyla, Finland. ${ }^{6}$ Centre for Primary Health Care, University of Basel, Basel, Switzerland.

\section{Received: 31 July 2020 Accepted: 20 November 2020}

\section{Published online: 28 November 2020}

\section{References}

1. Tung JY, Rose RV, Gammada E, Lam I, Roy EA, Black SE, et al. Measuring life space in older adults with mild-to-moderate Alzheimer's disease using mobile phone GPS. Gerontology. 2014;60(2):154-62.

2. Barnes LL, Wilson RS, Bienias JL, de Leon CFM, Kim HJN, Buchman AS, et al. Correlates of life space in a volunteer cohort of older adults. Exp Aging Res. 2007;33(1):77-93.

3. Rantakokko M, Portegijs E, Viljanen A, Iwarsson S, Kauppinen M, Rantanen T, Changes in life-space mobility and quality of life among communitydwelling older people: a 2-year follow-up study. Qual Life Res. 2016;25(5): 1189-97.

4. Tsai LT, Portegijs E, Rantakokko M, Viljanen A, Saajanaho M, Eronen J, et al. The association between objectively measured physical activity and lifespace mobility among older people. Scand J Med Sci Sports. 2015;25(4): e368-73.

5. Tsai LT, Rantakokko M, Rantanen T, Viljanen A, Kauppinen M, Portegijs E. Objectively measured physical activity and changes in life-space mobility among older people. J Gerontol a-Biol. 2016;71(11):1466-71.

6. Portegijs E, Rantakokko M, Viljanen A, Sipilä S, Rantanen T. Identification of older people at risk of ADL disability using the life-space assessment: a longitudinal cohort study. J Am Med Dir Assoc. 2016;17(5):410-4.

7. Lo AX, Brown CJ, Sawyer P, Kennedy RE, Allman RM. Life-space mobility declines associated with incident falls and fractures. J Am Geriatr Soc. 2014; 62(5):919-23.

8. Boyle PA, Buchman AS, Barnes LL, James BD, Bennett DA. Association between life space and risk of mortality in advanced age. J Am Geriatr Soc. 2010;58(10):1925-30.

9. Baker PS, Bodner EV, Allman RM. Measuring life-space mobility in community-dwelling older adults. J Am Geriatr Soc. 2003;51(11):1610-4.
10. Harada K, Lee S, Lee S, Bae S, Harada K, Suzuki T, et al. Objectively-measured outdoor time and physical and psychological function among older adults. Geriatr Gerontol Int. 2017;17(10):1455-62.

11. Hirsch JA, Winters M, Ashe MC, Clarke P, McKay H. Destinations that older adults experience within their GPS activity spaces relation to objectively measured physical activity. Environ Behav. 2016;48(1):55-77.

12. Münch M, Weibel R, Sofios A, Huang H, Infanger D, Portegijs E, et al. MOBllity assessment with modern TEChnology in older patients' real-life by the general practitioner: the MOBITEC-GP study protocol. BMC Public Health. 2019;19(1):1703.

13. Kerr J, Duncan S, Schipperjin J. Using global positioning Systems in Health Research a Practical Approach to data collection and processing. Am J Prev Med. 2011;41(5):532-40.

14. Pesyna KM, Robert WH, Humphreys WH. Accuracy in the palm of your hand GPS World. 2015;26(2):16-31.

15. Giannouli E, Bock O, Mellone S, Zijlstra W. Mobility in old age: capacity is not performance. Biomed Res Int. 2016;2016:3261567.

16. Hirsch JA, Winters M, Clarke P, McKay H. Generating GPS activity spaces that shed light upon the mobility habits of older adults: a descriptive analysis. Int J Health Geogr. 2014;13:51.

17. Stewart T, Duncan S, Chaix B, Kestens Y, Schipperijn J, Schofield G. A novel assessment of adolescent mobility: a pilot study. Int I Behav Nutr Phys Act. 2015;12:18.

18. Rainham D, McDowell I, Krewski D, Sawada M. Conceptualizing the healthscape: contributions of time geography, location technologies and spatial ecology to place and health research. Soc Sci Med. 2010; 70(5):668-76.

19. Sherman JE, Spencer J, Preisser JS, Gesler WM, Arcury TA. A suite of methods for representing activity space in a healthcare accessibility study. Int J Health Geogr. 2005;4:24

20. Chaix B, Kestens Y, Duncan S, Merrien C, Thierry B, Pannier B, et al. Active transportation and public transportation use to achieve physical activity recommendations? A combined GPS, accelerometer, and mobility survey study. Int I Behav Nutr Phys Act. 2014;11:124.

21. Fillekes MP, Kim EK, Trumpf R, Zijlstra W, Giannouli E, Weibel R. Assessing Older Adults' Daily Mobility: A Comparison of GPS-Derived and SelfReported Mobility Indicators. Sensors Basel. 2019;19(20):4551.

22. Zenk SN, Matthews SA, Kraft AN, Jones KK. How many days of global positioning system (GPS) monitoring do you need to measure activity space environments in health research? Health Place. 2018;51:52-60.

23. Laatikainen TE, Broberg A, Kytta M. The physical environment of positive places: exploring differences between age groups. Prev Med. 2017; 95(Suppl):S85-91.

24. Rantanen H, Kahila M. The SoftGIS approach to local knowledge. J Environ Manag. 2009;90(6):1981-90

25. Kyttä AM, Broberg AK, Kahila MH. Urban environment and children's active lifestyle: softGIS revealing children's behavioral patterns and meaningful places. Am J Health Promot. 2012;26(5):e137-48.

26. Chaix B, Kestens Y, Perchoux C, Karusisi N, Merlo J, Labadi K. An interactive mapping tool to assess individual mobility patterns in neighborhood studies. Am J Prev Med. 2012;43(4):440-50.

27. Hinrichs T, Keskinen KE, Pavelka B, Eronen J, Schmidt-Trucksass A, Rantanen T, et al. Perception of parks and trails as mobility facilitators and transportation walking in older adults: a study using digital geographical maps. Aging Clin Exp Res. 2019;31(5):673-683.

28. Haybatollahi M, Czepkiewicz M, Laatikainen T, Kytta M. Neighbourhood preferences, active travel behaviour, and built environment: an exploratory study. Transport Res F-Traf. 2015;29:57-69.

29. Kestens Y, Thierry B, Shareck M, Steinmetz-Wood M, Chaix B. Integrating activity spaces in health research: comparing the VERITAS activity space questionnaire with 7-day GPS tracking and prompted recall. Spat SpatioTemporal. 2018;25:1-9.

30. Zanda A. A map-based tool to measure older adults' life-space mobility: development, usability and evaluation; MSc thesis: Department of Geography, University of Zurich; 2017.

31. Swiss Federal Office of Topography swisstopo. Local Swiss reference frame LV03 [Available from: https://www.swisstopo.admin.ch/en/knowledge-facts/ surveying-geodesy/reference-frames/local/lv03.html. Accessed 1 Nov 2020

32. Zenk SN, Schulz AJ, Matthews SA, Odoms-Young A, Wilbur J, Wegrzyn L, et al. Activity space environment and dietary and physical activity behaviors: a pilot study. Health Place. 2011;17(5):1150-61. 
33. Carlson JA, Jankowska MM, Meseck K, Godbole S, Natarajan L, Raab F, et al. Validity of PALMS GPS scoring of active and passive travel compared with SenseCam. Med Sci Sports Exerc. 2015;47(3):662-7.

34. Klinker CD, Schipperijn J, Toftager M, Kerr J, Troelsen J. When cities move children: development of a new methodology to assess context-specific physical activity behaviour among children and adolescents using accelerometers and GPS. Health Place. 2015;31:90-9.

35. Vanwolleghem G, Schipperijn J, Gheysen F, Cardon G, De Bourdeaudhuij I, Van Dyck D. Children's GPS-determined versus self-reported transport in leisure time and associations with parental perceptions of the neighborhood environment. Int J Health Geogr. 2016;15(1):16.

36. UNESCO. International standard classification of education (ISCED). Paris: United Nations Educational, Scientific and Cultural Organization; 1997.

37. Fekete C, Siegrist J, Reinhardt JD, Brinkhof MWG. Is financial hardship associated with reduced health in disability? The case of spinal cord injury in Switzerland. PLoS One. 2014;9(2):e90130.

38. Lamb SE, Jorstad-Stein EC, Hauer K, Becker C. Development of a common outcome data set for fall injury prevention trials: the prevention of falls network Europe consensus. J Am Geriatr Soc. 2005;53(9):1618-22.

39. Folstein MF, Folstein SE, McHugh PR. "Mini-mental state". A practical method for grading the cognitive state of patients for the clinician. J Psychiatr Res. 1975;12(3):189-98.

40. Bland JM, Altman DG. Statistical methods for assessing agreement between two methods of clinical measurement. Lancet. 1986;1 (8476):307-10

41. McGraw KO, Wong SP. Forming inferences about some intraclass correlation coefficients. Psychol Methods. 1996;1 (1):30-46.

42. Bland JM. How can I decide the sample size for a study of agreement between two methods of measurement? 2004 [Available from: http://wwwusers.york.ac.uk/ mb55/meas/sizemeth.htm\#graph 2. Accessed 1 Nov 2020.

43. Landis JR, Koch GG. The measurement of observer agreement for categorical data. Biometrics. 1977;33(1):159-74.

44. Ullrich P, Werner C, Bongartz M, Kiss R, Bauer J, Hauer K. Validation of a modified life-space assessment in multimorbid older persons with cognitive impairment. Gerontologist. 2019;59(2):e66-75.

45. Roca RP, Klein LE, Kirby SM, McArthur JC, Vogelsang GB, Folstein MF, et al. Recognition of dementia among medical patients. Arch Intern Med. 1984; 144(1):73-5.

46. Shareck M, Kestens Y, Gauvin L. Examining the spatial congruence between data obtained with a novel activity location questionnaire, continuous GPS tracking, and prompted recall surveys. Int J Health Geogr. 2013;12:40.

47. Kestens Y, Thierry B, Shareck M, Steinmetz-Wood M, Chaix B. Integrating activity spaces in health research: comparing the VERITAS activity space questionnaire with 7-day GPS tracking and prompted recall. Spat Spatiotemporal Epidemiol. 2018;25:1-9.

48. Y\&R. Anteil der Besitzer von Smartphones bzw. Tablets in der Schweiz in den Jahren von 2013 bis 2018. Y\&R/Statista Hamburg: Statista GmbH; 2019 [Available from: https://de.statista.com/statistik/daten/studie/537944/ umfrage/besitz-von-smartphone-bzw-tablet-in-der-schweiz/. Accessed 1 Nov 2020.

49. Smith A, McGeeney K, Duggan M, Rainie L, Keeter S. US smartphone use in 2015. Pew Research Center: Pew Research Center; [Available from: http:// assets.pewresearch.org/wp-content/uploads/sites/14/2015/03/PI Smartphones_0401151.pdf. Accessed 1 Nov 2020.

\section{Publisher's Note}

Springer Nature remains neutral with regard to jurisdictional claims in published maps and institutional affiliations.

\section{Ready to submit your research? Choose BMC and benefit from}

- fast, convenient online submission

- thorough peer review by experienced researchers in your field

- rapid publication on acceptance

- support for research data, including large and complex data types

- gold Open Access which fosters wider collaboration and increased citations

- maximum visibility for your research: over $100 \mathrm{M}$ website views per year

At BMC, research is always in progress.

Learn more biomedcentral.com/submissions 